\title{
El niño con enfermedades infecciosas en las artes visuales: pintura
}

\section{The child with infectious diseases in the visual arts: painting}

\author{
Alejandro Donoso F. ${ }^{a}$, Daniela Arriagada S. ${ }^{a}$ \\ a Unidad de Paciente Crítico Pediátrico. Hospital Clínico Dra. Eloísa Díaz I. La Florida. Santiago. Chile
}

Recibido: 22 de mayo de 2019; Aceptado: 25 de julio de 2019

\begin{abstract}
Resumen
El impacto catastrófico de las enfermedades infecciosas sobre la salud infantil, como también el rol trascendental y benéfico aportado por la instauración y ejecución de medidas sanitarias y de inmunoprevención ha sido un tema recurrente en la historia de la medicina, aunque una vez logrado el control de la enfermedad, estas pasan fácilmente al olvido. Ante esto, parece necesario rememorar aquel escenario social mediante un acercamiento a través de la pintura. Las obras pictóricas son testigo de aquello, pues las enfermedades son objeto de representación y a su vez se han convertido en un invaluable documento en la historia de la medicina. Patologías pediátricas como tuberculosis, difteria, poliomielitis, sarampión, viruela y sífilis como también el inicio de la vacunación, son analizadas en diversas pinturas con el objetivo de profundizar el conocimiento de la época histórica, el autor y su vínculo con dicha enfermedad.
\end{abstract}

\begin{abstract}
The catastrophic impact of infectious diseases on children's health, as well the transcendental and beneficial role played by the establishment and execution of health measures and immunoprevention, has been a recurrent subject in the history of medicine, although once the disease has been controlled, they are easily forgotten. In view of this, it seems necessary to recall that social scenario through an approach through painting. The pictorial works are witnesses of that since diseases are subject of representation, and at the same time, they have become an invaluable document in the history of medicine. Pediatric pathologies such as tuberculosis, diphtheria, polio, measles, smallpox, and syphilis, as well as the initiation of vaccination, are analyzed in various paintings with the aim of deepening knowledge of the historical era, the author and his or her link to this disease.
\end{abstract}

Palabras clave: Infecciones; vacunas; historia de la medicina; humanidades; arte

\section{Keywords:}

Infections;

vaccines; medicine history; humanities; art 


\section{Introducción}

La crónica de las enfermedades es parte de la historia del arte y por ende del hombre. El empleo de la pintura para la evocación e interpretación de enfermedades, ha existido desde las antiguas civilizaciones hasta la época moderna ${ }^{1,2}$.

Mediante testimonios visuales, se conoce que en tiempos pasados las infecciones, infestaciones, epidemias y enfermedades carenciales eran difícilmente evitables, constituyendo el principal peligro para la población infantil ${ }^{3-6}$. Así, el arte se ha convertido en una fuente histórica que ha permitido el acercamiento a estas patologías y a su impacto en la población, como también del actuar de los médicos ante ellas.

El objetivo de esta publicación es estimular la curiosidad desde un punto de vista histórico-artístico sobre algunas enfermedades infecciosas infantiles plasmadas en pinturas, mediante el conocimiento de la obra, su autor y la época, ya que estas son el testimonio visual de la lucha del niño, su familia y la sociedad contra la enfermedad, el dolor y la muerte.

\section{Tuberculosis}

Esta enfermedad, por antonomasia causa de una muerte lenta y segura, originó efectos devastadores siendo llamada "la peste blanca" durante el siglo XIX. En la segunda mitad de aquel siglo, en pleno desarrollo de la revolución industrial, la tuberculosis alcanzó en Chile niveles de epidemia. En esa época se consideraba como una enfermedad hereditaria que amenazaba con degenerar la raza y se atribuía a factores sociales y ambientales, ya que atacaba con fuerza a la población más desvalida ${ }^{7}$.

El tratamiento y la prevención consistía en una adecuada alimentación, aire puro, trabajo moderado y el aislamiento de los enfermos en colonias escolares y sanatorios para su recuperación, ya que los medicamentos utilizados eran todos inútiles ${ }^{8}$.

En 1865, el médico francés Jean-Antoine Villemin inició sus experimentos para demostrar que la tuberculosis era una enfermedad infecciosa9. Pocos años después, el alemán Robert Koch describió al Mycobacterium tuberculosis como el patógeno causante (1882). En el siglo XX, Albert Calmette y Camille Guérin desarrollan la vacuna contra la tuberculosis (1921) y Albert Schatz y Selman Waksman descubren, a partir del hongo Streptomyces griseus, la estreptomicina (1943). Sin embargo, la verdadera revolución se provocó en 1952 con el desarrollo de la isoniacida, el primero de los antimicobacterianos específicos que conseguirían convertir a la tuberculosis en una enfermedad curable en la mayoría de los casos.

\section{Christian Krohg (1852-1925)}

Pintor noruego naturalista. Plasmó motivos de la vida diaria, explorando así la presencia de la enfermedad en la familia ${ }^{10}$.

La niña enferma de este cuadro (Figura 1) muestra su experiencia personal, pues la pintó tras la muerte de su hermana por tuberculosis, enfermedad que azotaba fuertemente a los países escandinavos en aquella época.

La hermana pálida de Krohg está iluminada de forma nítida y su cara no parece expresar tristeza ni desesperación, indicando que su muerte se acerca. En su regazo hay una rosa marchita y sus hojas caen como lágrimas sobre la manta que cubre sus piernas. La rosa significa la delicadeza de la vida, siendo un emblema inconfundible de su transitoriedad.

Krogh fue profesor y director de la Academia Noruega de Arte $^{10}$ y entre sus alumnos predilectos tuvo a Edvard Munch quién se inspiraría en el mismo motivo solo unos pocos años después (vide infra).

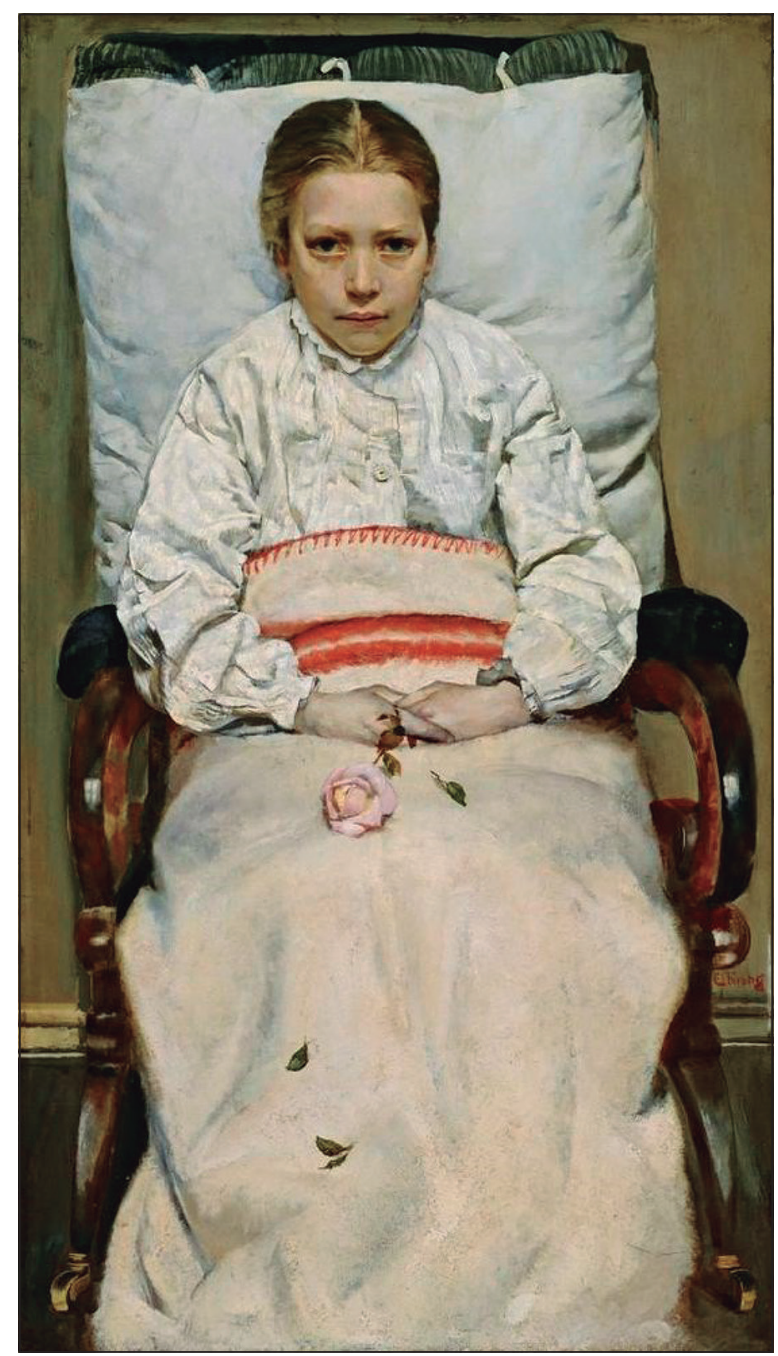

Figura 1. Christian Krogh. La niña enferma (Syk pike). 1880-81. Óleo sobre lienzo 102 × 58 cm. Galería Nacional. Oslo. Noruega. 


\section{Edvard Munch (1863-1944)}

Pintor y grabador noruego. Sus temáticas más frecuentes fueron relacionadas con los sentimientos de dolor, muerte y angustia ("El grito", 1893). Se le considera precursor del expresionismo ${ }^{11,12}$.

Munch tuvo un despegue definitivo como artista con la pintura "La niña enferma" (Figura 2), que refleja uno de los episodios más inquietantes de su vida, del cual nunca logró recuperarse, como fue la pérdida de su querida hermana mayor Sophie de 15 años, quien murió de tuberculosis (1877). Un evento catastrófico para su familia, ya que los niños habían perdido a su madre por la misma enfermedad.

La modelo para este trabajo fue una niña que Munch conoció en 1885 cuando acompañó a su padre médico a visitar a un niño con una pierna rota. Ella era la hermana del niño y al pintor le conmovió su desesperación ante el dolor de su hermano.

En esta pintura se aprecia a Sophie pálida y consumida por la enfermedad, recostada sobre un gran almohadón en su cama. Destaca la ausencia de suministros médicos en la habitación excepto una botella en una mesita de noche. El rojo anaranjado de los cabellos contribuye a acentuar la palidez de su rostro. Sin embargo, este transmite quietud, no así el personaje de su tía Karen, a quien se observa completamente desolada.

Esta obra es un cúmulo de pinceladas y colores que recuerda la respuesta emocional del artista y como él mismo diría: "No voy a pintar más interiores con hombres leyendo y mujeres tejiendo. Voy a pintar la vida de personas que respiran, sienten, sufren y aman". Para ello reconocía que "pinto de mi memoria las impresiones de mi infancia", "la niña enferma abrió caminos nuevos para mí, fue una ruptura en mi obra. La mayor parte de mis trabajos posteriores deben su existencia a este cuadro" 11 .

Con esta obra participó en la Exposición de Otoño de Oslo en 1886, causando cierto escándalo y rechazo entre la sociedad, no entendiéndose el dolor que expresaba aquella pintura para su vida, considerándose, además, tosca en su ejecución.

\section{Difteria}

Se señala al médico griego Areteo de Capadocia (siglo II d.c) como el primero en describir una epidemia de difteria ("úlcera siríaca o egipcia"). Esta enfermedad recibió en sus inicios nombres tan elocuentes como morbus suffocans, morbus strangulatorius, garrotillo, etc. ${ }^{13}$.

El médico Pierre Fidèle Bretonneau (1778-1862), basado en las observaciones de las epidemias ocurridas en Tours, Francia, le confirió a la enfermedad el nombre de difteritis (1821). Esta palabra deriva del

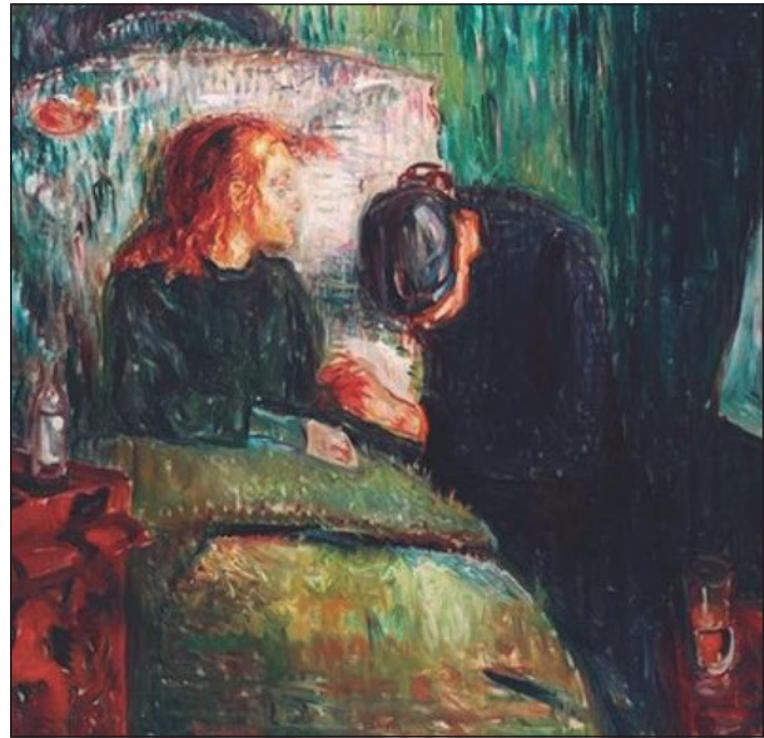

Figura 2. Edvard Munch. La niña enferma (Syk pike). 1885-86. Óleo sobre lienzo 119.4 x 118.7 cm. Galería Nacional. Oslo. Noruega.

griego diphtéra que significa "piel, membrana". Posteriormente, su discípulo Armand Trousseau amplió el conocimiento de su maestro señalando que no se trataba de una enfermedad inflamatoria local sino de una infección sistémica y cambió el nombre por difteria.

Según la teoría galénica, su origen estaba en lo espeso que se transformaban los humores con el frío, lo que provocaba obstrucción de las venas del cuello con inflamación y ulceración. Dado el mecanismo causal, el tratamiento sugerido era sangría y aplicación de emplastos calientes. Empero, el enfoque terapéutico cambió radicalmente cuando Löffler descubrió su agente causal, el bacilo Corynebacterium diphtheriae, en el año 1884.

En nuestro país, su letalidad alcanzó hasta un 30\%, siendo habitualmente ocasionada por obstrucción laríngea o su presentación "maligna"14. En relación a las medidas de soporte, ya en los años treinta se comenzaron a efectuar intubaciones para el croup diftérico, evidenciándose notorias ventajas por sobre la traqueostomía ${ }^{15}$.

En la actualidad es una enfermedad infrecuente en el mundo desarrollado, pero en los últimos años se han reportado miles de casos en África y el Sudeste asiático ${ }^{16}$.

\section{Francisco de Goya y Lucientes (1746-1828)}

Pintor europeo más importante de su tiempo ${ }^{17}$. Esta pintura representa una escena de "El Lazarillo de Tormes" (Figura 3). Corresponde al momento en que el amo ciego abre la boca del niño para comprobar, oliéndole, que se ha comido la longaniza que él estaba asando. 


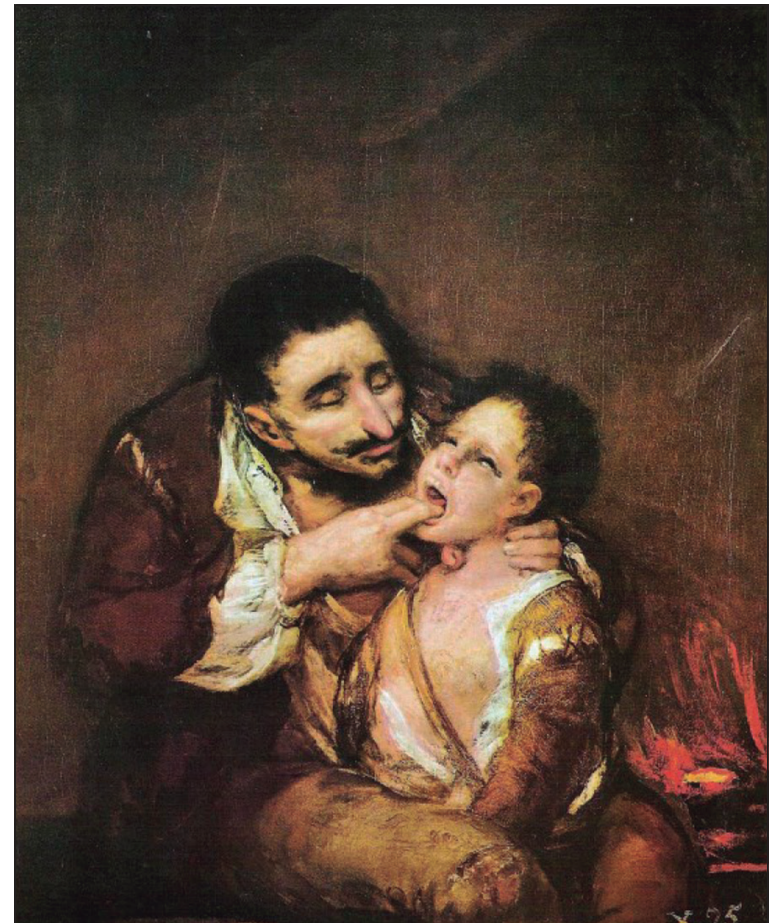

Figura 3. Francisco de Goya y Lucientes. El lazarillo de Tormes (antes llamado "El garrotillo). ca. 1808-10. Óleo sobre lienzo 80 x $65 \mathrm{~cm}$. Colección particular Madrid. España.

Muchos años más tarde, el Dr. Gregorio Marañón (1887-1960) la denominó como "El Garrotillo", nombre con el que se conocía popularmente a la difteria ${ }^{18}$. De la misma manera que el garrote vil provocaba la compresión del cuello (al torcer el lazo que lo rodea), la difteria producía una asfixia lenta.
El afamado médico se basó en la observación de una práctica bastante común en aquella época, como era el intentar arrancar las pseudomembranas con los dedos o cauterizar el tejido ante la desesperación que provocaba contemplar la lenta agonía de los niños, principales víctimas de la infección.

En detalle, se observa un ambiente oscuro, iluminado por las llamas de un fuego, a un hombre de aspecto descuidado quién sujeta entre sus piernas a un niño vestido con harapos, tomándolo por el cuello con su mano izquierda, mientras le introduce dos de sus dedos en la garganta. Los ojos del niño muestran lo incómodo de la maniobra. Esta pintura se ha convertido en una imagen clásica de difteria.

\section{Georges Chicotot (1868-1921)}

Pintor y médico radiólogo. Elaboró pinturas que mostraban actos médicos innovadores ${ }^{19}$. Esta escena (Figura 4) ocurre paradójicamente en el Hospital Bretonneau de París (vide supra). Se aprecia, en el centro, al pediatra Dr. Albert Josias (1855-1906) quién, para evitar una cruenta traqueostomía, está practicando la intubación con un tubo metálico a un paciente que se asfixia por difteria. El niño se encuentra "aparentemente tranquilo" mientras está sentado en la falda de la enfermera y es inmovilizado por hombros y cabeza. A la derecha, otro médico quién es el único que no mira el procedimiento, se encuentra preparando el suero anti-diftérico, que se había elaborado poco más de una década antes por Emil von Behring.

El Dr. Chicotot murió a consecuencia de la sobreexposición a los rayos $\mathrm{X}$, como la mayoría de los primeros radiólogos.
Figura 4. Georges Chicotot. La intubación (Le tubage). 1904. Óleo sobre lienzo130 x $180 \mathrm{~cm}$. Museo de la Asistencia Pública Hospital de París.

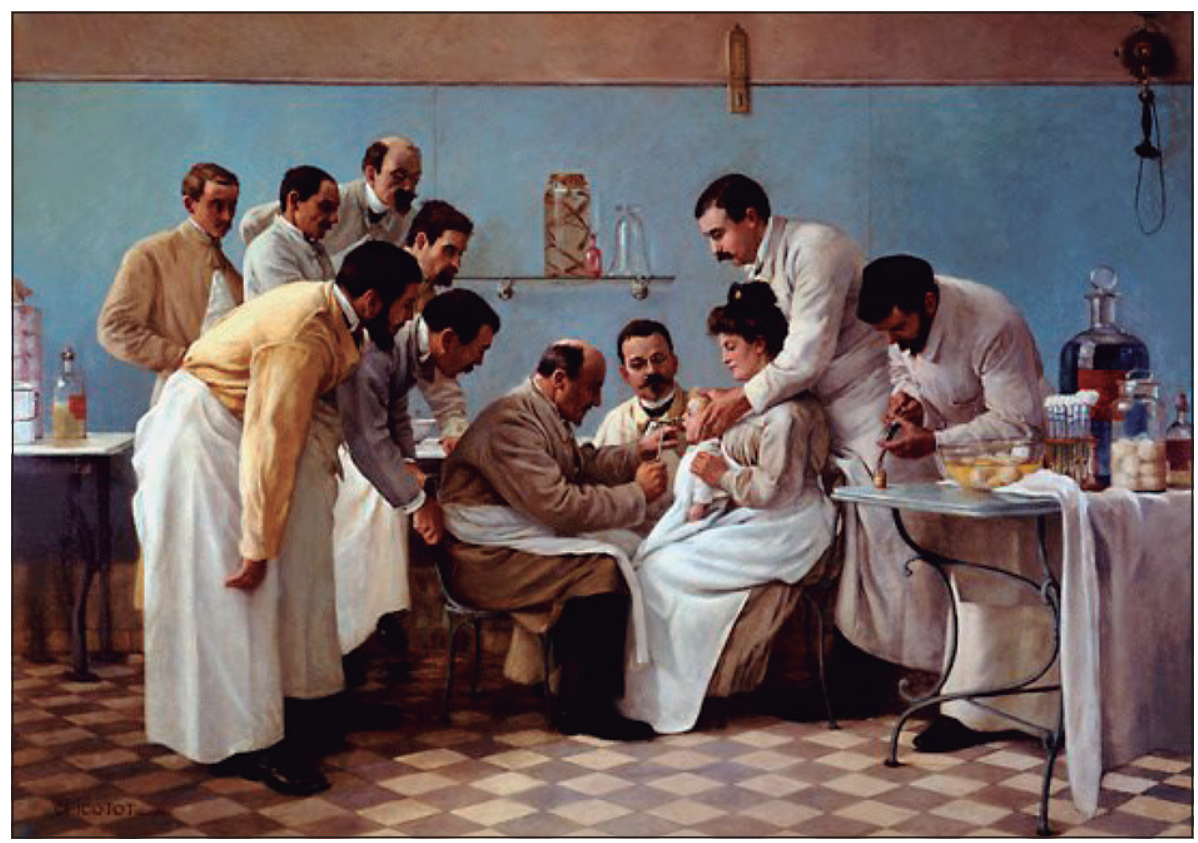




\section{Poliomelitis}

Existe evidencia de que se trata de una enfermedad muy antigua, siendo casi seguro que fue conocida por los egipcios, pues en los bajorrelieves descubiertos en la pirámide Zakkar, se destacan jóvenes con las secuelas de la enfermedad ${ }^{6}$.

El testimonio gráfico más difundido es procedente de una estela egipcia funeraria de 1400 a.C. Sin embargo, recién una década posterior a la pintura aquí comentada, los doctores Flexner, Lewis, Landsteiner y Popper descubrieron que el agente infeccioso de la poliomielitis era un virus.

La poliomielitis era muy frecuente en los meses cálidos y aunque la mayoría de las personas se recuperaba rápidamente, algunas sufrían parálisis temporal o permanente y muchas de ellas morían. Los sobrevivientes de la polio quedaban discapacitados de por vida, y eran un recuerdo visible y doloroso para la sociedad.

Se debe señalar que el desarrollo de la ventilación mecánica y el inicio de los cuidados intensivos fueron la respuesta a la desastrosa epidemia de poliomielitis que afectó a Europa a mediados del siglo pasado ${ }^{20}$. En Chile, la poliomielitis produjo cientos de casos durante la década de 1950 y comienzos de los años 60, por lo que en 1961 comenzó la vacunación con Polio Sabin oral, lo cual eliminó esta enfermedad, siendo Chile el tercer país en el mundo en lograr su erradicación ${ }^{6}$.

En la actualidad, se ha reducido en un $99 \%$ el número de casos de poliomielitis y al contrario que la mayoría de las enfermedades infecciosas, la poliomielitis sí puede erradicarse completamente, con una vacunación universal de la población infantil.

\section{Joaquín Sorolla Bastida (1863-1923)}

Gran maestro del luminismo español, elaboró una serie de obras de denuncia social ${ }^{21}$. En esta pintura ( $\mathrm{Fi}$ gura 5) aparece un grupo de niños enfermos del asilo de San Juan de Dios bañándose en la playa del Cabañal en Valencia. El sacerdote está ayudando a un niño que camina con muletas cuyas extremidades inferiores están atrofiadas, lo que se asemeja a las secuelas de la poliomielitis. Además, aparecen dos niños con muletas, uno de ellos en el mar y un niño ciego el cual extiende su brazo derecho. Inicialmente, este cuadro iba a titularse como "Los hijos del placer" en alusión a las teorías psiquiátricas degeneracionistas de creciente fama en esa época en Europa ${ }^{22}$ según las cuales, la pérdida de la autoridad moral de los padres y la "vida promiscua y disipada" de éstos llevaba a contraer "enfermedades vergonzosas", que finalmente degeneraban en graves problemas de salud para sus hijos.

Cabe destacar el color azul añil del mar en el cual se bañan estos niños marginados de la sociedad, lo que contrasta con el habitual alegre colorido y luminosidad de las escenas de playa en otras obras del mismo autor. El cuadro se presentó con gran éxito en la Exposición Universal de París de 1900.

\section{Viruela-Vacunación}

Una de las más temibles enfermedades ha sido la viruela, causante de estragos en todo el mundo, especialmente en América, donde fue uno de los factores que diezmó a la población nativa ${ }^{23}$. Quienes sobrevivían durante el proceso de curación desarrollaban graves secuelas deformantes de por vida ("picado de viruela").

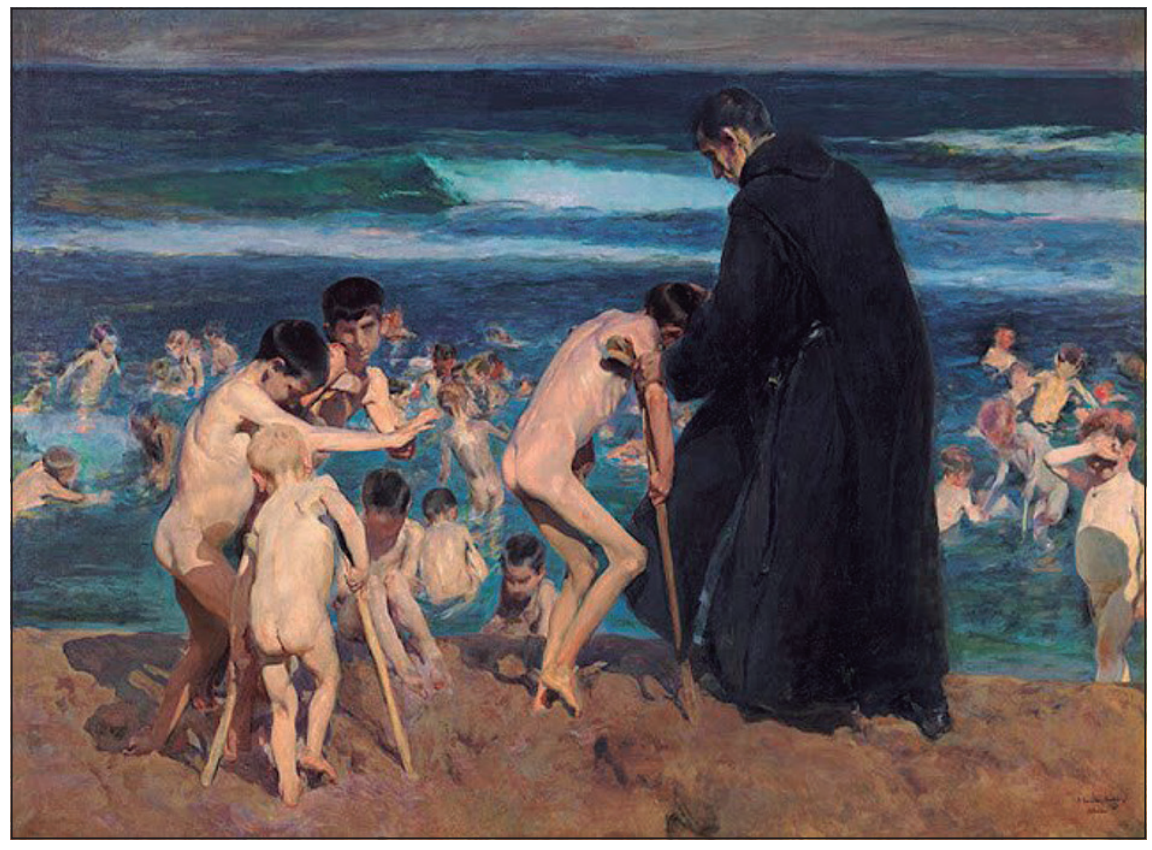

Figura 5. Joaquín Sorolla. Triste herencia. 1899. Óleo sobre lienzo 212 × 288 cm. Colección privada. Bancaja, Valencia. España. 
La vacuna desarrollada por el médico rural, ornitólogo y poeta inglés Edward Jenner (1749-1823) a finales del siglo XVIII, representa un punto de inflexión en la historia de la humanidad. El día 14 de mayo de 1796 en la localidad de Berkeley, inoculó el exudado de una pústula de viruela bovina extraída directamente de las ampollas de la mano de la ordeñadora Sarah Nelmes en el brazo izquierdo del niño de ocho años, James Phipps. Semanas después demostró la inmunidad del niño inoculándole una muestra de viruela fresca.

Pero esta historia no comienza ahí, sino muchos años antes, en 1716 cuando la escritora Lady Mary Wortley Montagu, esposa del embajador inglés y quién había sufrido esta enfermedad, llegó a Constantinopla donde se percató que las ancianas turcas infectaban deliberadamente a los niños con pus de enfermos de viruela, quienes posterior a una semana presentaban escasos síntomas, para quedar luego inmunizados. En su retorno a Inglaterra en 1721, extendió la "tradición turca" a las coronas europeas y defendió esta vía de prevención (variolización) a pesar de la oposición de la comunidad científica y religiosa, quienes la catalogaron como "herejía musulmana" 24.

En su monumental obra Historia general de Chile, don Diego Barros Arana señala a la epidemia de 1561 como la aparición de la enfermedad, situación ocurrida con el arribo de don Francisco de Villagra a la Serena $^{3,25}$. Centenarios después, a inicios del siglo XX, el Dr. Luis Calvo Mackenna aconsejaba a las madres en su "Cartilla de Puericultura al alcance del pueblo" lo siguiente: "No se conoce ninguna otra manera de evitar la viruela que el procedimiento de la vacunación, ..." "su efecto es tan seguro...", "... hay que vacunarse tan pronto como se pueda...” y terminó su recomendación contando que el mismo "...se ha vacunado ya seis veces y todavía no cuenta 30 años de vida".

En 1980 la Organización Mundial de la Salud declaró a la viruela como una enfermedad erradicada.

\section{Vicente Borrás y Abellá (1867-1945)}

Pintor y restaurador español, sus obras se caracterizan por una intensa luminosidad ${ }^{26}$. Este óleo (Figura 6) muestra el momento de la vacunación antivariólica en un centro sanitario a fines del siglo XIX. En un primer plano se aprecia la cabeza de un caballo recostado (algunos ven una vaca), el cual está atado sobre una mesa, señalándonos el origen de la vacuna. Atrás, el anciano médico está inoculando a un niño, el cual es sostenido por su madre. A la derecha varios niños desnudos y asustados (uno de los cuales evoca un querubín) esperan su turno junto a sus madres. Además, surge una interesante reflexión de lo aquí representado, la mujer quién se encuentra elegantemente vestida con un traje y tocado rojo, con exuberantes joyas contrasta con las otras madres que impresionan de un origen humilde. Esto refleja que, gracias a la medicina preventiva no existe barrera social, ya que todas tienen un interés común, la salud de sus hijos ${ }^{27}$.

\section{Sífilis}

Girolamo Fracastoro (1478-1553), fue un médico, poeta, astrónomo y geólogo nacido en la ciudad Veneciana de Verona. En 1530 publicó, inspirado en una historia de Ovidio, el poema "Syphilis sive de morbo gallico libri tres" (Los tres libros de la sífilis o el mal francés). Es aquí donde acuñó el nombre con el cual se conoce actualmente esta enfermedad ${ }^{28}$.

Figura 6. Vicente Borrás y Abellá. Vacunación de niños. ca. 1900. Óleo sobre lienzo 100 x $150 \mathrm{~cm}$. Museo Nacional del Prado. Madrid.

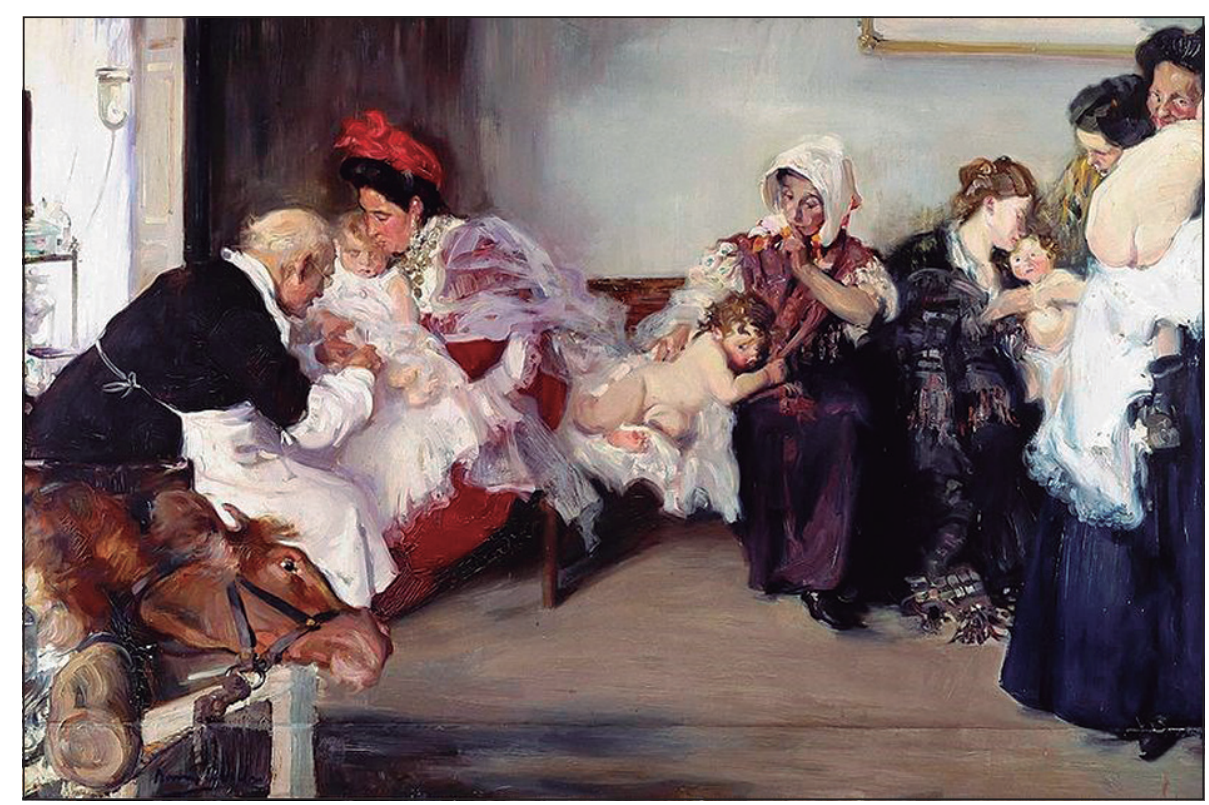


El impacto de la sífilis fue enorme desde aquella época hasta antes de la introducción de la penicilina a mediados del siglo XX. Su causa se atribuyó a los más diversos mecanismos, tanto naturales como sobrenaturales ("un castigo a la vida licenciosa"). Del mismo modo, los diversos tratamientos indicados constituyen de por sí un sabroso capítulo en la historia de la medicina ${ }^{29}$.

Muy poco después de la realización de esta pintura, en 1905, el protozoólogo Fritz Schaudinn y el dermatólogo Erich Hoffman descubrieron a la Spirochaeta pallidum como la causante de esta enfermedad ${ }^{30}$.

La transmisión madre a hijo puede ocurrir en cualquier etapa del embarazo, siendo el adecuado tratamiento de la madre con sífilis la medida más costo efectiva. Actualmente presenta una tasa de 0.1 por mil nacidos vivos en nuestro país ${ }^{31}$.

\section{Edvard Munch (1863-1944)}

Una madre sentada en la consulta del médico llora con su hijo en el regazo, el cual está evidentemente enfermo. Su piel es intensamente pálida y presenta exantema macular. Es aquí donde podemos reconocer algunas características de la sífilis congénita (Figura 7). Sin embargo, en esta época la causa de la enfermedad era desconocida.

Como se ha señalado (vide supra) la vida de Edvard Munch estuvo marcada por la tragedia humana; estando este tema presente en su obra pictórica ${ }^{11,12}$.

Particularmente esta pintura fue mal recibida por la crítica, situación que no importó en demasía al autor, lo que se evidencia al revisar su correspondencia con un amigo médico ${ }^{11}$. Probablemente por ser una enfermedad de transmisión sexual, era un tema tabú, y quienes la padecían (incluyendo los niños) eran prontamente estigmatizados por la sociedad. Munch sentía una especial predilección por los niños enfermos, retratándolos frecuentemente.

\section{Sarampión}

El libro de 1877 "Medicina doméstica de la infancia o sea consejos a las madres. Sobre el modo de criar, cuidar, educar i curar a sus hijos por si mismas" del doctor Wenceslao Hidalgo, lo cataloga como una de las fiebres eruptivas de la primera infancia, recomendado como tratamiento el reposo, dieta y "tomar bebidas sudoríficas i musilajinosas"32. No obstante, también señalaba que el tratamiento de las complicaciones debe ser dirigido por un médico, pues en ocasiones eran de mayor gravedad que la enfermedad ${ }^{32}$. Esto se confirmó a comienzos del siglo pasado, cuando miles de niños chilenos fallecían por epidemias de "alfombrilla", lo cual motivó la creación del primer hospital infantil en nuestro país ${ }^{4}$.

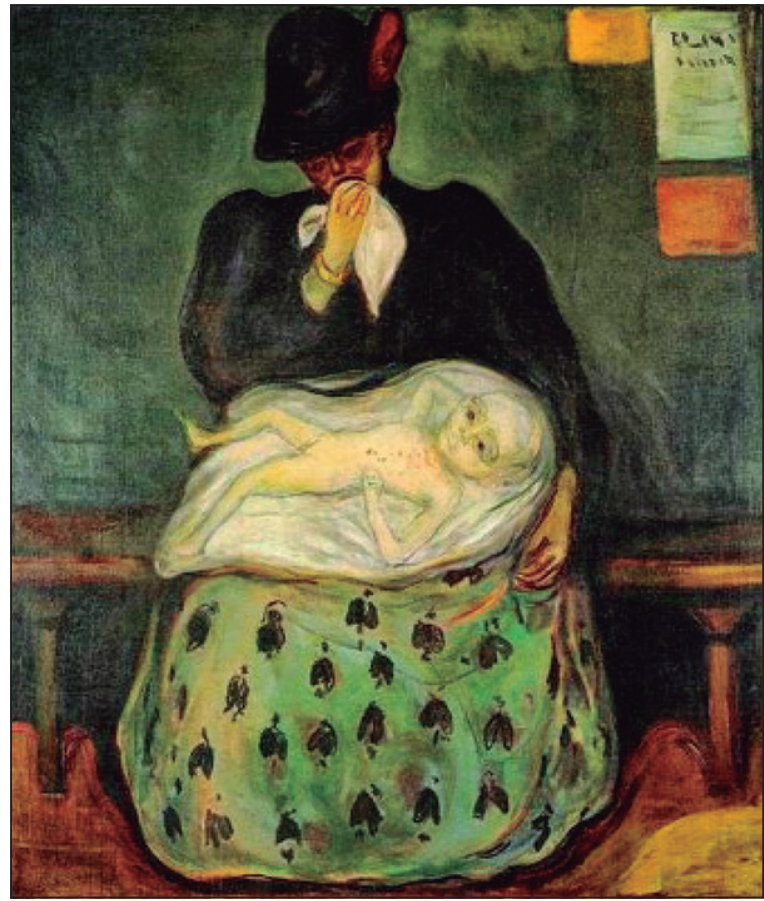

Figura 7. Edvard Munch. La herencia (Arv). ca. 1897-99. Óleo sobre lienzo 141 x $120 \mathrm{~cm}$. Museo Munch. Oslo. Noruega.

Actualmente, ha transcurrido más de medio siglo desde la utilización de una vacuna efectiva, empero, siguen existiendo cientos de muertes diarias en el mundo, describiéndose una letalidad de 1 por 1000 casos $^{33}$. Esta enfermedad altamente contagiosa, pero inmunoprevenible, aún afecta a países desarrollados, fenómeno motivado por una reducción de su cobertura ${ }^{34}$.

\section{Pedro Lira (1845-1912)}

Nació en Santiago de Chile. Se caracterizó por cultivar diversas temáticas en su disciplina, entre las cuales reflejó la vida cotidiana ${ }^{35,36}$.

En esta pintura naturalista (Figura 8) se aprecia en un ambiente de pobreza, a dos mujeres cuidando de un niño enfermo. Una de ellas está vertiendo, probablemente, algún tipo de remedio natural casero en una taza mientras la otra, con evidente preocupación en el rostro, lo sostiene en su enfaldo.

Aunque no se tiene certeza si este niño adolecía de una enfermedad infecciosa, lo más probable es que así fuese. A inicios del siglo pasado, la población chilena alcanzaba cifras levemente superiores a los tres millones de personas, existía un $60 \%$ de analfabetismo, con ausencia de medidas de saneamiento básico y la tasa de mortalidad infantil era de 340 por cada 1000 na$\operatorname{cidos}_{\text {vivos }}{ }^{37}$. Durante la infancia, los principales problemas eran dados por el tifus, sarampión y difteria. Además, la muerte de los niños era mirada como una parte inevitable de la vida, incorporando este aconteci- 
Figura 8. Pedro Lira. El niño enfermo. 1902 Óleo sobre tela $100 \times 137 \mathrm{~cm}$. Museo Nacional de Bellas Artes. Santiago. Chile.
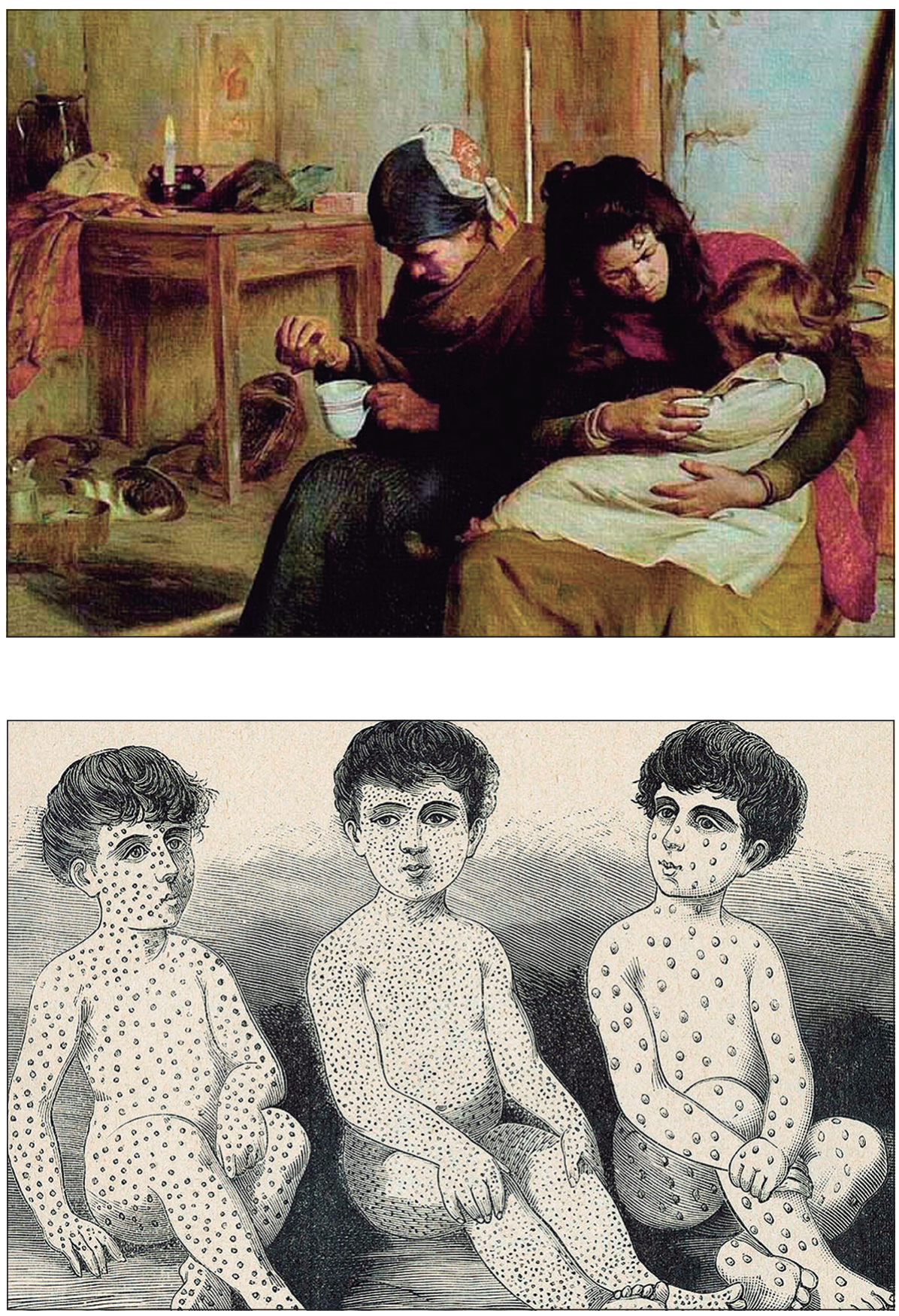

Figura 9. Grabado de autor anónimo. Extraído desde Les Remèdes de la Bonne Femme. ca 1880. Mary Evans Picture Library.

miento al folklore, constituyéndose como un símbolo cultural y antropológico. Así, el "velorio del angelito o despedimiento" se constituyó en un rito de los sectores populares ${ }^{37}$, especialmente en la sociedad rural y campesina. ${ }^{36}$.

Pedro Lira es reconocido como uno de los maestros de la pintura chilena. Entre sus premios destacan la mención honrosa en el Salón de París (1882) y la segunda Medalla de Plata en la Exposición Universal de París de 1889 por su obra "La Fundación de Santiago".

\section{Anónimo}

El niño de la izquierda es quién tiene sarampión (rougeole). En este grabado (Figura 9) se presenta el característico exantema máculo-papular generalizado (color rojo vinoso), el cual se inicia en la cabeza, cara y región retroauricular para luego cursar una distribución centrífuga por tronco y extremidades. Su duración es entre 3 a 5 días, para finalmente desaparecer en el mismo orden en el cual se inició. A manera de comparación el niño del centro tiene escarlatina y el de la derecha varicela. 


\section{Discusión}

La representación de las enfermedades infantiles en la sociedad ha dejado un rastro indeleble a lo largo de la historia del arte. Particularmente, a la pintura debiésemos entenderla como una magnífica vitrina para acercarnos y conocer el impacto de la enfermedad en la historia de la humanidad.

En Chile, la alta mortalidad infantil durante el siglo XIX e inicios del XX, era un hecho cotidiano y natural; esta "mortalidad de párvulos" se explicaba por múltiples factores como voluntad divina (ergo, algo ineludible), herencia, idiosincrasia popular, variaciones climáticas y geográficas, el bajo nivel de las condiciones de vida (en ocasiones miserables) y la irresponsabilidad de las madres quienes habitualmente "los medicaban o consultaban a un charlatán o médica yerbatera" ${ }^{38}$. Además, se atribuyó su causalidad como un costo de la modernización, lo que provocaba que "se perdiera el vigor y se adquirieran vicios". Todo esto se veía reafirmado en el poco éxito de la ciencia en la salud por aquella época ${ }^{39}$. Por último, paradójicamente a los enfermos se los estigmatizaba y culpaba de ser "una afrenta para el país" y "sentencia de muerte para nuestro porvenir nacional"

En la actualidad resulta difícil comprender y entender el gran impacto que significaban las enfermedades infecciosas en el pasado ${ }^{41}$ pero tampoco se debe olvidar que la vacunación es, probablemente, el acto humano que más vidas ha salvado en la historia de la humanidad. A través de esta mirada creemos que el médico logrará un mejor conocimiento de la huella de las enfermedades infecciosas en el pasado, como también del exitoso trabajo en búsqueda de su erradicación. No obstante, la lucha todavía continua para algunas de ellas $^{34}$.

\section{Conflicto de intereses}

Los autores declaran no tener conflicto de intereses.

\section{Referencias}

1. Aris A. La Medicina en la pintura. Barcelona: Lundwerg Editores;2002.

2. González J. La historia oculta de la humanidad: un recorrido a través de las enfermedades infecciosas. Barcelona: Ars Medica: 2006. p. 311.

3. Laval E. Cincuentenario de la última epidemia de viruela en Chile. Rev Chilena Infect. 2000;17(4):344-6.

4. Laval E. La epidemia de sarampión de 1899-1900 en Chile y la creación del primer hospital de niños de Santiago. Rev Chilena Infectol. 2002;19:121-3.

5. Laval E. Epidemia de tifus exantemático en Chile (1932-1939). Rev Chilena Infect. 2013;30:313-6.

6. Laval E. Anotaciones para la historia de la poliomielitis en Chile. Rev Chilena Infectol. 2007;24(3):247-50.

7. Herrera T, Farga V. Historia del Programa de Control de la Tuberculosis de Chile. Rev Chil Enferm Respir. 2015;31:227-31.

8. De la Figuera Von Wichmann E. Las enfermedades más frecuentes a principios del siglo XIX y sus tratamientos. Disponible en https://ifc.dpz.es/recursos/ publicaciones/29/16/11figuera.pdf. Accedido el día 16 de abril 2019.

9. Études sur la Tuberculose; Preuves Rationnelles et Expérimentales de sa Spécificité et Son Inoculabilité. París: J. B. Bailliere; 1868.

10. Thue O. Christian Krohg. Norsk kunstnerleksikon. Disponible en https:// nkl.snl.no/Christian_Krohg. Accedido el día 8 de abril 2019.

11. Bischoff U. Edvard Munch: Cuadros sobre la vida y la muerte. Madrid: Benedikt Taschen Verlag; 2011.

12. Miranda MC, Miranda EC, Molina M. Edvard Munch: enfermedad y genialidad en el gran artista noruego. Rev Med Chile. 2013;141:774-9.

13. Laval E. El garotillo (Difteria) en España (Siglos XVI y XVII). Rev Chilena Infectol. 2006;23:78-80.

14. Schonhaut L, Guiloff S. Experiencia de 100 intubaciones y 100 traqueotomías en asfixia por Crup diftérico. Rev Chil Ped. 2013;84(3):326-31.

15. Izzo C. La intubación en el croup diftérico en el niño. Rev Chil Ped.1935; 241-54.

16. WHO. Global Health Observatory (GHO) data. Disponible en http://www.who.int/ gho/immunization/en/. Accedido el día 29 de marzo 2019.

17. Hagen RM, Hagen R. Goya. Alemania: Editorial Taschen GmbH;2016.

18. Laín P. Gregorio Marañón. Vida, obra y persona. Madrid: Espasa Calpe;1969.

19. Nardin A. Progrès de la médecine infantile, Histoire par l'image [en ligne], Disponible en http://www.histoireimage. org/fr/etudes/progres-medecine-infantile Accedido el 10 de abril 2019.

20. West JB. The physiological challenges of the 1952 Copenhagen poliomielitis epidemic and a renaissance in clinical respiratory physiology. J Appl Physiol (1985). 2005;99(2):424-32

21. García-Bermejo F. Joaquín Sorolla. Barcelona: Editorial Poligrafa; 2006.

22. Galton F, Watson HW. On the Probability of the Extinction of Families. J Royal Anthropological Institute 1874;4:138-44.

23. Laín P. Historia Universal de la Medicina. Barcelona: Salvat Editores;1975.

24. Wortley M. Letters from the Levant, during the Embassy to Constantinople 1716-18. Londres: Joseph Rickerby, Sherbourn Lane; 1763.

25. Ferrer PL. Historia general de la medicina en Chile:(documentos inéditos, biografías y bibliografías): desde el descubrimiento y conquista de Chile, en 1535 hasta nuestros días. Desde 1535, hasta la inauguración de la Universidad de Chile en 1843. Talca: Imprenta Talca de J. Martín Garrido, 1904. Capitulo XX p. 253-68.

26. Fundación Amigos Del Museo Del Prado. «Borrás Abellá, Vicente». Accedido el día 15 abril 2019.

27. Texto extractado de Reyero C. "Vacunación de niños", Ternura y Melodrama. Pintura de escenas familiares en tiempos de Sorolla. Conselleria de Educacio y Cultura, 2003. p. 228.

28. Echeverría V. Girolamo Fracastoro y la invención de la sífilis.História, Ciências, Saúde-Manguinhos 2010;17(4):877-4.

29. Quiroga M. Una aproximación a las diversas facetas sobre la sífilis en Chile durante la segunda mitad del siglo XIX. Cuadernos de Historia Cultural, Crítica y Reflexión. Disponible en https:// cuadernosdehistoriacultural.files. wordpress.com/2013/03/01-macarenazamorano-sc3adfilis.pdf. Accedido el 16 de abril 2019.

30. Medina-De la Garza C, Koschwitz M, Velasco-Castañón JG. Fritz Schaudinn: 
zoólogo y protozoologo. Medicina Universitaria 2012;14(57):231-8.

31. Cáceres K, Martínez R. Syphilis epidemiological report. Chile, 2016. Rev Chilena Infectol. 2018;35(3):284-96.

32. Hidalgo W. Medicina domestica de la infancia o sea consejos a las madres. Santiago: Imprenta de la Librería del Mercurio; 1877. p. 289. Disponible en http://www.memoriachilena.gob.cl/ archivos2/pdfs/MC0059631.pdf. Accedido el día 23 de abril 2019.

33. Delpiano L, Astroza L, Toro J. Sarampión: la enfermedad, epidemiología, historia y los programas de vacunación en Chile. Rev Chilena Infectol. 2015;32(4):417-29.

34. Cerda J, Abarca K, Jiménez J. Brotes de sarampión en países desarrollados: Una lección para Chile. Rev Chilena
Infectol.2015; 32(3): 326-8.

35. Allamand AF. Pintura chilena del siglo XIX. Pedro Lira el Maestro Fundador. Santiago: Origo Ediciones;2008.

36. Romera A. Historia de la pintura chilena. Santiago: Editorial del Pacífico S.A;1951.

37. Rojas J. Segundo período, 1840-1890: la infancia en el estado liberal. Mortalidad infantil y rituales funerarios. En: Historia de la infancia en el Chile republicano, 1810-2010. Primera edición; Santiago: JUNJI. p. 108-16. Disponible en https:// www.aacademica.org/jorge.rojas.flores/9. pdf. Accedido el día 20 de abril 2019.

38. Zorrilla P. "Reseña de las causas de la mortalidad de los niños en Santiago i medios de evitarlas". Comunicación de don Pablo Zorrilla a la Facultad de
Medicina", Anales de la Universidad de Chile, tomo XVIII, Santiago, 1861, p. 455460.

39. D. “Algunas ideas sobre la excesiva mortalidad de los párvulos i medios profilácticos que podrían emplearse", en El médico práctico, Santiago, № 2, $19 /$ dic./1867, pp. 12-14; $\mathrm{N}^{\circ} 3$, 2/enero/1868, pp. 20-22; No $5,9 /$ marzo/1868, pp. 33-36.

40. Calderón A. Cuando Chile cumplió 100 años. Santiago: Quimantú; 1973. p.36. Disponible en http://www. memoriachilena.gob.cl/archivos2/pdfs/ mc0013341.pdf. Accedido el día 22 de abril 2019.

41. Manterola M, Yañez JP, Ríos V. Diario de Lucía Manterola 1903-1927: Una joven tuberculosa. Santiago: Dedal de Oro; 2011. 